\title{
How to Pattern a Leaf
}

\author{
N. Bolduc,,$^{1,2}$ D. O’Connor, ${ }^{2}$ J. Moon, ${ }^{2}$ M. Lewis, ${ }^{2}$ and S. HAKe ${ }^{1,2}$ \\ ${ }^{1}$ Plant Gene Expression Center, USDA-ARS, Albany, California 94710 \\ ${ }^{2}$ Department of Plant and Microbial Biology, University of California, Berkeley, California 94720 \\ Correspondence: hake@berkeley.edu
}

\begin{abstract}
Leaf development presents a tremendous resource for tackling the question of patterning in biology. Leaves can be simple or highly dissected. They may have elaborated parts such as the tendrils of a pea leaf or the rolled blade of a carnivorous pitcher plant. Despite the variation in size, shape, and function, all leaves initiate in the same manner: from the flanks of a meristem. The maize leaf is useful for analysis of patterning due to the wealth of mutants and the distinct tissues along the proximal distal axis. The blade is distal, the sheath is proximal, and the ligule forms at the blade/sheath boundary. Establishment of this boundary involves the transcription factors LIGULELESS1 and LIGULELESS2 and the kinase LIGULELESS NARROW. The meristem-specific protein KNOTTED1 (KN1) binds and modulates the lg2 gene. Given the localization of KN1 at the proximal end of the leaf from the time of inception, we hypothesize that KN1 has a role in establishing the very proximal end of the leaf, whereas an auxin maximum guides the growing distal tip.
\end{abstract}

Meristems are self-organizing groups of cells located at the growing tips of plants. Shoot meristems have two zones: a self-renewing central zone that contains the "stem cells" and a peripheral zone, also called the morphogenetic zone, where organogenesis begins. Leaves initiate as flattened bulges on the flank of the meristem with inherent cues at inception. An innate proximal distal axis exists by the very nature of being attached to the meristem. Because the emerging leaf encircles the meristem, adaxial-abaxial polarity is also inherent to the growing organ; the inner half faces the stem cells of the meristem and the outer half faces away from the meristem.

Because organs form in defined phyllotactic patterns, it is possible to predict the position of a leaf before it initiates. These "initial cells" are marked by distinct gene expression patterns, one of which is the specific downregulation of knox (knottedl-like homeobox) gene expression (Jackson et al. 1994). knox genes are expressed throughout the meristems of all plants and down-regulated in leaf initial cells (Fig. 1). In plants with simple leaves, knox expression remains off throughout leaf development. In species with dissected leaves such as tomato or Cardamine, knox genes are down-regulated in initial cells, but expression returns in leaf primordia (Bharathan et al. 2002; Hay and Tsiantis 2006). The level of dissection is correlated with knox expression (Hareven et al. 1996; Hay and Tsiantis 2006; Shani et al. 2009). Thus, one way to elaborate leaf shape is to express meristem genes in the leaf (Blein et al. 2008).

Loss-of-function mutants for knox genes demonstrate that these genes are essential for meristem function. In the shootmeristemless mutant of Arabidopsis, true leaves fail to form and the shoot terminates (Barton and Poethig 1993; Long et al. 1996). A slightly less severe phenotype is seen in osh 1 mutants in rice, in which three leaves form before the meristem terminates (Tsuda et al. 2011).
Severity of the knotted $1(\mathrm{knl})$ loss-of-function phenotype in maize depends on genetic background. In some inbreds, such as W22, the shoot quits after forming zero to two leaves. In other inbreds, the plant makes a full complement of leaves but shows a loss of lateral organ initiation from inflorescence meristems (Kerstetter et al. 1997; Vollbrecht et al. 2000). In these permissive backgrounds, removal of additional knox genes, such as rough sheath1, leads to termination of the shoot at germination, illustrating the redundancy of knox genes (N Bolduc and $\mathrm{S}$ Hake, unpubl.). These results tell us that $k n o x$ genes are needed for the coordination of meristem maintenance and leaf initiation.

\section{THE ROLE OF KN1 IN PROXIMAL DISTAL PATTERNING}

Gain-of-function mutants have revealed a role for knox genes in leaf patterning. knox mutants are abundant in maize, perhaps due to the wealth of active transposons, but they have also been found in barley (Müller et al. 1995) and Antirrhinum (Golz et al. 2002). Kn1 mutants have arisen in maize due to tandem duplications (Veit et al. 1990; Ramirez et al. 2009) and insertions in introns (Hake et al. 2004). Similar to wild-type plants, gene expression disappears in initial cells; however, it returns in Kn1 leaf primordia.

The timing and location of $k n l$ expression result in different phenotypes that are best understood in the context of normal leaf development. The sheath is a proximal tissue that wraps around the stem while the blade tilts back to optimize photosynthesis. At the boundary of the blade and sheath are the ligule and auricle, tissues found in all grasses (Fig. 2A). Most dominant Kn1 mutants misexpress $k n l$ along the lateral veins, causing the cells 

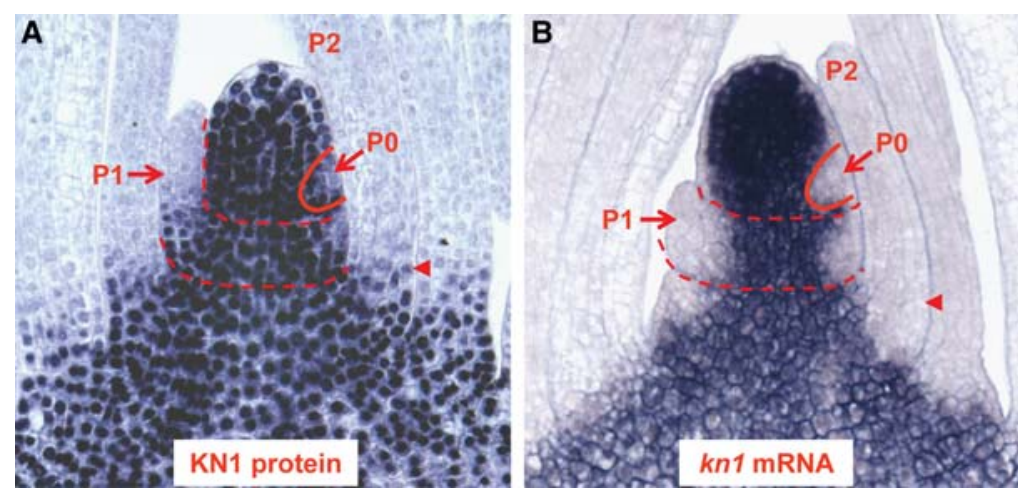

Figure 1. KN1 protein and mRNA in the maize shoot apical meristem (SAM). (A) KN1 immunolocalization showing expression in the SAM and at the base of leaves (arrowhead). (B) knl messenger RNA (mRNA) in situ hybridization. Plastochron 0 (P0) contains the initial cells for the next leaf. The P1 leaf wraps around the meristem (dotted lines). The arrowhead points in the same position as in $A$, showing that the protein has moved into the base of the leaf beyond the domain of mRNA accumulation.

to continue to divide and differentiate as sheath and auricle instead of blade, thus producing "knots" (Fig. 3A) (Freeling and Hake 1985; Sinha and Hake 1990). Expression at the margins leads instead to the appearance of flaps with sheath and auricle cell identity along the blade margin (Fig. 3B,C) (Ramirez et al. 2009). When knox gene expression continues from the stem into the leaf, the blade/sheath boundary is displaced into the distal (blade) tissue (Foster et al. 1999).

To interpret these phenotypes, it is important to remember that KN1 marks the proximal end of a leaf from the time of inception (Fig. 1). knl misexpression in the distal blade causes the cells to adopt sheath cell identity, recreating the blade/sheath pattern of a wildtype leaf, but perpendicular to the normal axis. When misexpressed at the margin of the blade, growth occurs and sheath tissue expands beyond the normal boundaries of the blade. These phenotypes demonstrate that KN1 specifies proximal cues when expressed in distal tissues. Considering the strong accumulation of KN1 in the most proximal part of the leaf (Fig. 1), including from the time of inception in the $\mathrm{P} 0$, we infer that $\mathrm{KN} 1$ is involved in the specification of the proximal axis of the leaf during normal development.

If KN1 specifies the very proximal end of a leaf, what specifies the distal end? Just as KN1 expression disappears in initial cells, PIN1 proteins that transport auxin are expressed at high levels in these very cells. In Arabidopsis, a single PIN1 protein transports auxin through the epidermis to the initial cells, creating a maximum of
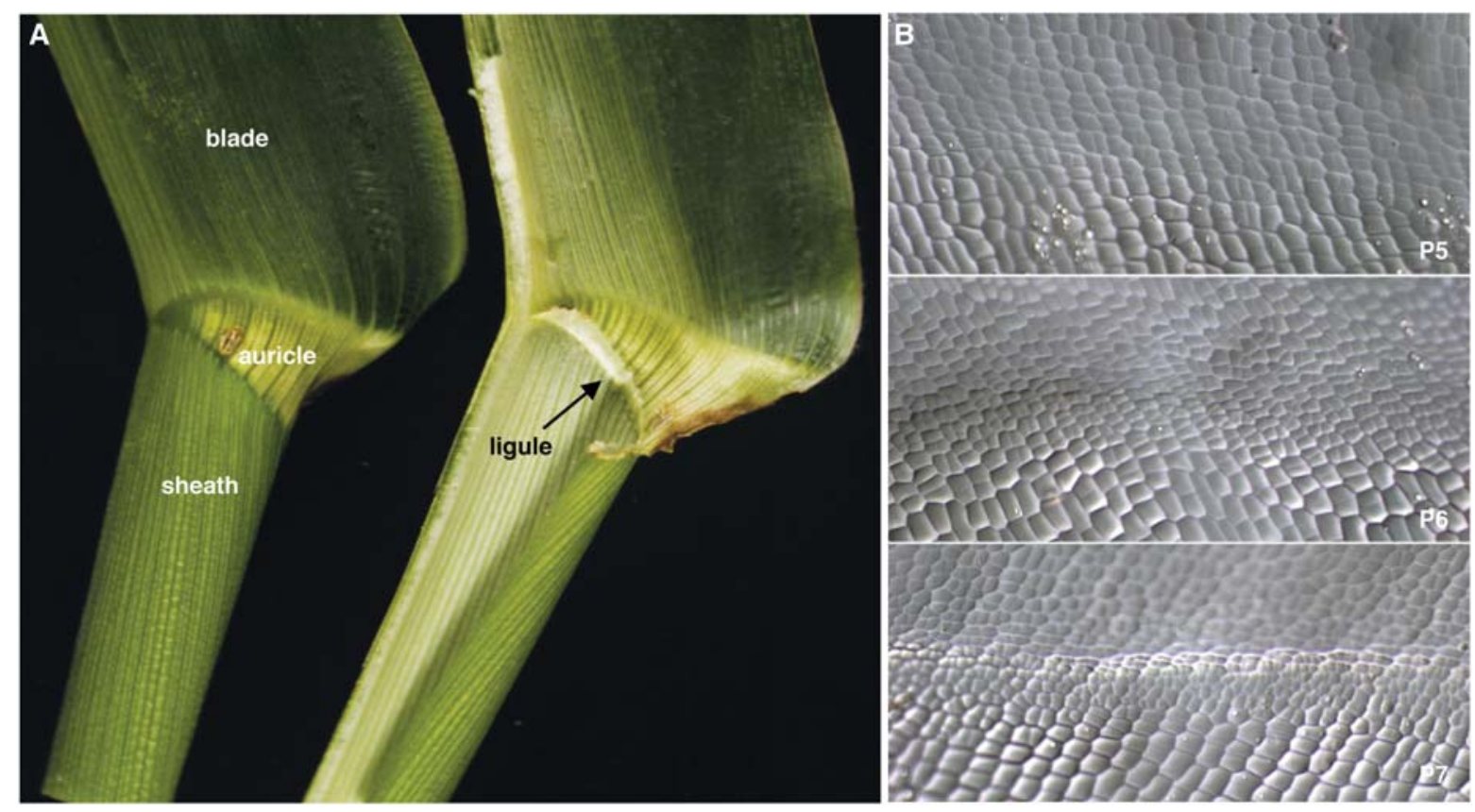

Figure 2. The ligule region of the maize leaf. (A) Abaxial (left) and adaxial (right) view of a maize leaf. (B) Divisions at the preligule band. (Top) Plastochron 5 (P5) leaf, (middle) P6 leaf, (bottom) P7 leaf of a 2-wk-old B73 seedling. 


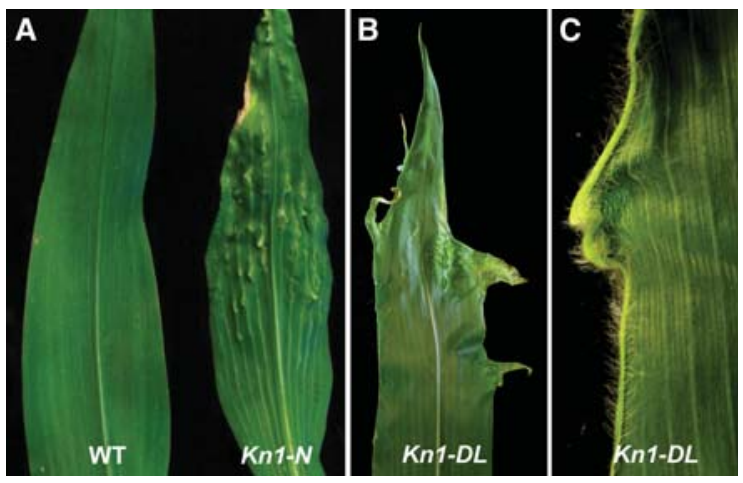

Figure 3. Knotted 1 phenotypes. (A) KnI-N features knots and clear veins. $(B, C) K n 1-D L$ displays flaps at leaf margins.

auxin accumulation (Scarpella et al. 2006; Bayer et al. 2009). The same PIN1 protein transports auxin away from the meristem into internal tissues, creating the primary vascular strand. In maize and Brachypodium, a PIN1 protein that is lost in the Brassicaceae (which includes Arabidopsis), Sister of PIN1 (SoPIN1), is expressed in the epidermis, moving auxin toward the maximum at the site of initial cells. Two other PIN1 proteins, PIN1a and PIN1b, move auxin away from the initial cells, creating an auxin channel (Fig. 4B,C) (D O'Connor, et al., unpubl.). Auxin activity can also be visualized using the auxin reporter DR5 (Gallavotti et al. 2008), which is expressed across the growing margin of a leaf primordium, clearly marking the distal margin of the leaf (Fig. 4A).

The expression of KN1 and PIN1 proteins is not mutually exclusive. KN1 accumulates in vasculature of the stem, where PIN1 expression is high. KN1 and SoPIN1 proteins are also both found in the epidermis, but interestingly, $k n 1$ messenger RNA (mRNA) is absent in these cells (Jackson et al. 1994). Experiments that compare mRNA and protein expression in maize shoots show that the protein extends beyond the cells where mRNA is located (Fig. 1) (Jackson 2002). In 1994, we speculated that the $\mathrm{KN} 1$ protein moved into the epidermis from underlying cells (Jackson et al. 1994). It is now well established that $\mathrm{KN} 1$ does traffic from one cell to another through plasmodesmata (Kim et al. 2003; Xu et al. 2011). Because this mRNA/protein difference is not found in Arabidopsis meristems and PIN1 subfunctionalization was lost in the Brassicaceae (D O'Connor, et al., unpubl.), it is possible that KN1 moves into the epidermis to specifically regulate SoPIN1. Why would KN1 move rather than just be transcribed in the epidermis? One possibility is that auxin activity may repress transcription of knox genes (Scanlon 2003; Hay et al. 2006). Another possibility is that movement through plasmodesmata provides a mechanism to regulate the abundance of KN1 protein.

We used gain-of-function mutants and a transgenic reporter for PIN1a to observe the interaction of KN1 and auxin in leaves, where $\mathrm{KN} 1$ is normally absent. In regions at which $k n l$ is misexpressed, cells between the parallel veins begin expressing PIN1a, suggesting that new veins are being initiated. Later, veins perpendicular to the normal leaf axis form, following the reorientation of growth (D O'Connor and S Hake, unpubl.). These results suggest that KN1 activity leads to de novo PIN1a expression. One then wonders the extent to which this interaction is direct. Does KN1 first promote auxin accumulation that then results in PIN1 expression or does KN1 primarily affect auxin transport directly?

To unravel the role KN1 has in setting up the proximal axis of a leaf and to determine whether KN1 directly regulates PIN1 proteins, we performed chromatin immunoprecipitation (ChIP) and RNA-seq (RNA sequencing) experiments (Bolduc et al. 2012). Our binding studies took advantage of a KN1-specific antibody in ChIP-seq experiments using inflorescence primordia where $\mathrm{KN} 1$ is abundant. We performed RNA-seq experiments aimed at identifying the genes differentially expressed between normal and $k n l$ loss-of-function tassel primordia, ear primordia, and shoot apices. We also queried gene expression differences in leaf primordia between normal and gain-of-function $\mathrm{Kn} 1-\mathrm{N}$ mutants before the appearance of phenotypic differences. ChIP-seq analysis identified several thousand genomic regions significantly enriched in each of the two inflorescence samples, including known targets such as ga2oxl (Bolduc and Hake 2009).

We found that KN1 binds and modulates mostly transcription factors and genes involved in hormone biology, particularly genes in the auxin pathway. Notably, KN1 binds all four pinl genes, but not other pin genes. Indeed, pinla and sopin1 are up-regulated in gain-of-function Knl-N leaves. Many other auxin-related genes are bound
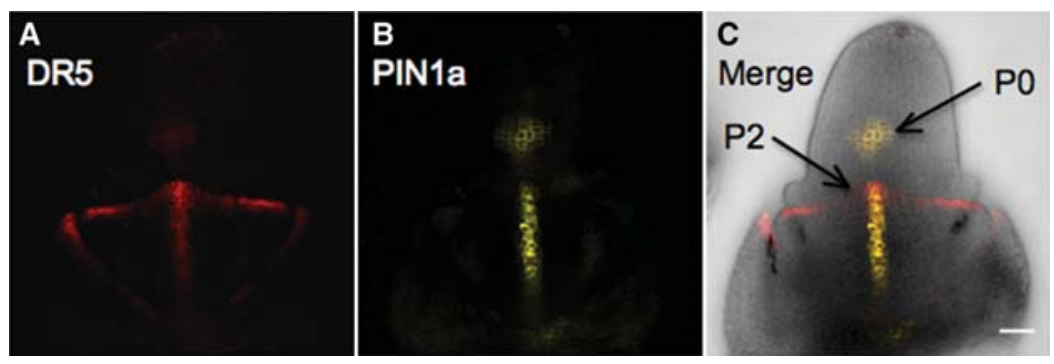

Figure 4. Auxin activity in the vegetative meristem and P2 leaf primordium. $(A)$ DR5::mRFP, $(B)$ PIN1a::Citrine, and $(C)$ merged with bright field; P0 and P2 leaves are labeled. Scale bar, $50 \mu \mathrm{M}$. 
and modulated (Bolduc et al. 2012); thus, it remains to be determined whether the regulation of PIN1 proteins is primarily due to $\mathrm{KN} 1$ direct regulation or secondary to increased auxin signaling. Regardless, the intimate connection between KN1 and auxin activity provides important clues as to how knox genes may function to initiate and maintain pattern formation.

\section{DRAWING A LINE IN A FIELD OF CELLS}

The boundary between blade and sheath, marked by the ligule and auricle, is established very early in the leaf primordium. The first visible sign of the blade/sheath boundary is a band of rapidly dividing cells (Fig. 2B). Cell divisions begin in the transverse and longitudinal directions, creating many small cells. Periclinal divisions follow the initial wave of division and create the ridge that will develop into the ligule (Sylvester et al. 1990). The preligule band is $\sim 50$ cells from the meristem when periclinal divisions are first visible ( $\mathrm{R}$ Johnston and $\mathrm{M}$ Scanlon, pers. comm.). Thus, it is likely that the initial signaling specifying the position of the preligule band is established only a few cells from the meristem. This close proximity suggests that the ligule position is established in part by cues from the meristem, perhaps through signaling from KNOX proteins.

Mutants have been useful for understanding how the preligule band forms in a field of seemingly identical cells. Two classic mutants that are missing ligules are liguleless $1(\lg 1)$ and liguleless $2(\lg 2)$. The $\lg 1-R$ mutation removes the ligule and auricle from most of the leaves, but the blade/sheath boundary remains distinct (Sylvester et al. 1990). lg2-R mutants lack ligules and auricles on the first initiated leaves but recover ligule and auricle at the margins on later initiated leaves (Harper and Freeling 1996). lg1 encodes a squamosa-promoter binding protein (Moreno et al. 1997), whereas $\lg 2$ encodes a basic leucine zipper protein (Walsh et al. 1998). Another mutant that removes the ligule is Liguleless narrow (Lgn). This semidominant phenotype is very background dependent. In the background of B73, the mutant produces narrow leaves with only a patch of ligule at the midrib. Outside the midrib region, the distinction between blade and sheath is not sharp, with stretches of sheath in the blade and vice versa. Homozygotes in any inbred are very severe and never reach maturity. The $\operatorname{lgn}$ gene encodes a putative serine threonine kinase with a small extracellular domain (J Moon, H Candela-Anton, and S Hake, unpubl.).

It has been hypothesized that the ligule signal begins near the center and moves toward the margins. Preligule cell divisions are first visible to the left and right of the midrib and later at the margins and over the midrib (Sylvester et al. 1990). In addition, mosaic analysis shows that sectors of $\lg 1$ mutant tissue lack the ligule and auricle, but the ligule that forms to the outside of the sector is often displaced proximally (Becraft et al. 1990; Becraft and Freeling 1991). Because leaves differentiate from the tip to the base, this proximal displacement is a sign that the ligule at the margin initiates later in time. Third, the ligule and auricles that develop at the margins of $\lg 2$ mutant leaves are often displaced relative to one another, as if the coordinating information is lost. Finally, the middle of the leaf differentiates first and the margins last, so it is more likely that the positional information comes from the middle of the leaf rather than from the margins.

To begin to place these genes in a pathway, expression and double mutant analyses were performed. $\lg n$ and $\lg 2$ are expressed broadly, including in the meristem (M Scanlon, pers. comm.). In contrast, $\lg 1$ is expressed exclusively in the line where the preligule forms ( $\mathrm{J}$ Moon, $\mathrm{H}$ Candela-Anton, and S. Hake, unpubl.). $\lg 1$ and $\lg 2$ mRNA levels are decreased in Lgn mutants (J Moon, H Candela-Anton, and S Hake, unpubl.) and $\lg 1$ levels are also decreased in $\lg 2$ mutants (Walsh et al. 1998). Double mutants were generated in backgrounds where Lgn heterozygotes are mild with only a reduced auricle. The $\lg 1$ Lgn double mutants were synergistic, completely lacking a blade/sheath boundary. The $\lg 2$ Lgn doubles were also synergistic but not as severe (J Moon, H Candela-Anton, and S Hake, unpubl.). Given the domain of expression, the mutant phenotypes, and the assumption that the blade/sheath boundary initiates from the center, it is likely that the LG2 transcription factor has a critical role in initiating or propagating the signal. Other factors must replace LG2 at the margins but fail to compensate for the coordinating function of LG2. LGN is required outside of the midrib domain to transmit the preligule signal. It is also needed for proper medial/lateral expansion of the leaf. LG1 is needed to initiate periclinal divisions but may have a redundant role in boundary formation because double mutants with Lgn are synergistic.

A remaining question is what links the proximal distal pattern to the preligule signaling. $\lg n$ is weakly bound by $\mathrm{KN} 1$ and not modulated, whereas $\lg 2$ is moderately bound and up-regulated in $K n 1-N$ leaves as well as down-regulated in $k n 1$ loss-of-function ears (Bolduc et al. 2012). These results suggest a direct and positive KN1-mediated regulation of $\lg 2$. Thus, the timing of expression and regulation by KN1 suggest that LG2 is an important link among proximal distal signaling cues from the meristem to ligule induction.

\section{CONCLUSIONS}

Maize leaves are composed of a proximal sheath and a distal blade, with ligule and auricle in between the two. We hypothesize that KN1 establishes the proximal end of the leaf, given its expression pattern and gain-offunction phenotypes. Direct KN1 targets that may function in proximal distal patterning are the four pin 1 genes, $\lg 2$, $\lg n$, and other proximal genes such as yabby genes that are misexpressed in Knl-N leaves (Bolduc et al. 2012). LG2 is likely to be an important player in setting up proximal distal patterning given its relationship to KN1 and its role in specification of ligule development. 


\section{ACKNOWLEDGMENTS}

We thank members of the Hake lab for lively discussion and Robert Mandrell for use of his confocal microscope. This work was supported by NSF grant MCB1052051.

\section{REFERENCES}

Barton MK, Poethig RS. 1993. Formation of the shoot apical meristem In Arabidopsis thaliana - an analysis of development in the wild type and in the shoot meristemless mutant. Development 119: 823-831

Bayer EM, Smith RS, Mandel T, Nakayama N, Sauer M, Prusinkiewicz P, Kuhlemeier C. 2009. Integration of transportbased models for phyllotaxis and midvein formation. Genes Dev 23: 373-384.

Becraft PW, Freeling M. 1991. Sectors of liguleless-1 tissue interrupt an inductive signal during maize leaf development. Plant Cell 3: 801-807.

Becraft PW, Bongard-Pierce DK, Sylvester AW, Poethig RS, Freeling M. 1990. The liguleless-1 gene acts tissue specifically in maize leaf development. Dev Biol 141: 220-232.

Bharathan G, Goliber TE, Moore C, Kessler S, Pham T, Sinha NR. 2002. Homologies in leaf form inferred from KNOXI gene expression during develoment. Science 296: $1858-$ 1860.

Blein T, Pulido A, Vialette-Guiraud A, Nikovics K, Morin H, Hay A, Johansen IE, Tsiantis M, Laufs P. 2008. A conserved molecular framework for compound leaf development. Science 322: $1835-1839$.

Bolduc N, Hake S. 2009. The maize transcription factor KNOTTED1 directly regulates the gibberellin catabolism gene ga2ox1. Plant Cell 21: 1647-1658.

Bolduc N, Yilmaz A, Mejia-Guerra MK, Morohashi K, O’Connor D, Grotewold E, Hake S. 2012. Unraveling the KNOTTED1 regulatory network in maize meristems. Genes Dev (in press).

Foster T, Yamaguchi J, Wong BC, Veit B, Hake S. 1999. Gnarley is a dominant mutation in the knox4 homeobox gene affecting cell shape and identity. Plant Cell 11: 1239-1252.

Freeling M, Hake S. 1985. Developmental genetics of mutants that specify Knotted leaves in maize. Genetics 111: 617-634.

Gallavotti A, Yang Y, Schmidt RJ, Jackson D. 2008. The relationship between auxin transport and maize branching. Plant Physiol 147: 1913-1923.

Golz JF, Keck EJ, Hudson A. 2002. Spontaneous mutations in $K N O X$ genes give rise to a novel floral structure in Antirrhinum. Development 12: 515-522.

Hake S, Smith HMS, Holtan H, Magnani E, Mele G, Ramirez J. 2004. The role of KNOX genes in plant development. Annu Rev Cell Dev Biol 20: 125-151.

Hareven D, Gutfinger T, Parnis A, Eshed Y, Lifschitz E. 1996. The making of a compound leaf: Genetic manipulation of leaf architecture in tomato. Cell 84: 735-744.

Harper L, Freeling M. 1996. Interactions of liguleless1 and liguleless 2 function during ligule induction in maize. Genetics 144: $1871-1882$.

Hay A, Tsiantis M. 2006. The genetic basis for differences in leaf form between Arabidopsis thaliana and its wild relative Cardamine hirsuta. Nat Genet 38: 942-947.

Hay A, Barkoulas M, Tsiantis M. 2006. ASYMMETRIC LEAVES1 and auxin activities converge to repress BREVIPEDICELLUS expression and promote leaf development in Arabidopsis. Development 133: 3955-3961.
Jackson D. 2002. Double labeling of KNOTTED1 mRNA and protein reveals multiple potential sites of protein trafficking in the shoot apex. Plant Physiol 129: 1423-1429.

Jackson D, Veit B, Hake S. 1994. Expression of maize KNOTTED1 related homeobox genes in the shoot apical meristem predicts patterns of morphogenesis in the vegetative shoot. Development 120: 405-413.

Kerstetter RA, Laudencia-Chingcuanco D, Smith LG, Hake S. 1997. Loss of function mutations in the maize homeobox gene, knotted1, are defective in shoot meristem maintenance. Development 124: 3045-3054.

Kim JY, Yuan Z, Jackson D. 2003. Developmental regulation and significance of KNOX protein trafficking in Arabidopsis. Development 130: 4351-4362.

Long JA, Moan EI, Medford JI, Barton MK. 1996. A member of the KNOTTED class of homeodomain proteins encoded by the SHOOTMERISTEMLESS gene of Arabidopsis. Nature 379: $66-69$.

Moreno MA, Harper LC, Krueger RW, Dellaporta SL, Freeling M. 1997. liguleless 1 encodes a nuclear-localized protein required for induction of ligules and auricles during maize leaf organogenesis. Genes Dev 11: 616-628.

Müller K, Romano N, Gerstner O, Garcia-Maroto F, Pozzi C, Salamini F, Rohde W. 1995. The barley Hooded mutation caused by a duplication in a homeobox gene intron. Nature 374: $727-730$.

Ramirez J, Bolduc N, Lisch D, Hake S. 2009. Distal expression of knotted 1 in maize leaves leads to re-establishment of proximal/distal patterning and leaf dissection. Plant Physiol 151: $1878-1888$.

Scanlon MJ. 2003. The polar auxin transport inhibitor N-1naphthylphthalamic acid disrupts leaf initiation, KNOX protein regulation, and formation of leaf margins in maize. Plant Physiol 133: 597-605.

Scarpella E, Marcos D, Friml J, Berleth T. 2006. Control of leaf vascular patterning by polar auxin transport. Genes Dev 20: 1015-1027.

Shani E, Burko Y, Ben-Yaakov L, Berger Y, Amsellem Z, Goldshmidt A, Sharon E, Ori N. 2009. Stage-specific regulation of Solanum lycopersicum leaf maturation by class 1 KNOTTED1-LIKE HOMEOBOX proteins. Plant Cell 21: $3078-$ 3092.

Sinha N, Hake S. 1990. Mutant characters of Knotted maize leaves are determined in the innermost tissue layers. Dev Biol 141: 203-210.

Sylvester AW, Cande WZ, Freeling M. 1990. Division and differentiation during normal and liguleless-1 maize leaf development. Development 110: 985-1000.

Tsuda K, Ito Y, Sato Y, Kurata N. 2011. Positive autoregulation of a KNOX gene is essential for shoot apical meristem maintenance in rice. Plant Cell 23: 4368-4381.

Veit B, Vollbrecht E, Mathern J, Hake S. 1990. A tandem duplication causes the KnI-O allele of Knotted, a dominant morphological mutant of maize. Genetics 125: 623631.

Vollbrecht E, Reiser L, Hake S. 2000. Shoot meristem size is dependent on inbred background and presence of the maize homeobox gene, knotted1. Development 127: 3161 3172.

Walsh J, Water CA, Freeling M. 1998. The maize gene liguleless 2 encodes a basic leucine zipper protein involved in the establishment of the leaf blade-sheath boundary. Genes Dev 12: $208-218$.

Xu XM, Wang J, Xuan Z, Goldshmidt A, Borrill PG, Hariharan N, Kim JY, Jackson D. 2011. Chaperonins facilitate KNOTTED1 cell-to-cell trafficking and stem cell function. Science 333: $1141-1144$. 


\section{$\$_{\text {CSH }}^{\infty}$ Cold Spring Harbor Symposia SYMPOSIA On Quantitative Biology}

\section{How to Pattern a Leaf}

N. Bolduc, D. O'Connor, J. Moon, et al.

Cold Spring Harb Symp Quant Biol 2012 77: 47-51 originally published online November 21, 2012

Access the most recent version at doi:10.1101/sqb.2012.77.014613

References This article cites 34 articles, 26 of which can be accessed free at: http://symposium.cshlp.org/content/77/47.full.html\#ref-list-1

\section{License}

Email Alerting

Receive free email alerts when new articles cite this article - sign up in

Service the box at the top right corner of the article or click here. 